\title{
A Rare Case of Young Hypertension- Disease Beyond the Arch
}

\author{
Mani Agila Saravanan ${ }^{1}$, Kilakuthotipalayam Pushparaju Sowmiya ${ }^{2}$ \\ ${ }^{1}$ Assistant Professor, Department of Medicine, Government Royapettah Hospital/Government Kilpauk Medical \\ College, Chennai, Tamilnadu, India. ${ }^{2}$ Postgraduate Student, Department of Internal Medicine, Government Royapettah \\ Hospital/Government Kilpauk Medical College, Chennai, Tamilnadu, India.
}

\section{INTRODUCTION}

Mid Aortic Syndrome (MAS) is a rare condition which occurs in children and young adults causing severe hypertension. Severe segmental narrowing of the abdominal aorta and descending thoracic aorta is the characteristic feature. It maybe congenital or acquired. We report a 19-year-old girl who presented to us with severe hypertension caused by MAS. Significant narrowing of the abdominal aorta and renal arteries was identified in CT angiogram. This signifies that in young patients with severe hypertension, it is of utmost importance to do a thorough and aggressive search with further imaging studies to rule out secondary hypertension. This helps to treat young hypertensives before the complications develop. Mid aortic syndrome is characterised by severe segmental narrowing of the abdominal aorta and descending thoracic aorta with high propensity for both visceral and renal artery involvement. Among all the cases of aortic narrowing, MAS accounts for $0.5-2 \%{ }^{1}$ Congenital MAS results due to defect in fusion of embryonic dorsal aorta which usually occurs during the fourth week of gestation. ${ }^{2}$ MAS usually presents with uncontrolled hypertension, followed by headache, claudication, dyspnoea, abdominal angina and failure to thrive.

\section{PRESENTATION OF CASE}

A 19-year-old girl was admitted with complaints of headache and giddiness for 1 week. On examination, her blood pressure was 180/100 $\mathrm{mmHg}$ in both upper limbs and $160 / 90$ in both lower limbs. Examination of cardiovascular and respiratory systems were normal. On per abdominal examination, a bruit was heard over the epigastric region. Patient was started on amlodipine, atenolol and prazosin. No substantial decrease in BP was observed. Investigations showed normal renal parameters; echocardiography showed concentric LVH; TFT was within normal limits; ANA- negative, ESR- 5/17, CRP- 24 mg/dl, USG abdomen: Normal sized kidney with normal echoes. Doppler: narrowing of abdominal aorta at the level of SMA and bilateral origin of renal artery. Parvus et tardus pattern of flow in bilateral intra renal arteries. MRI abdomen with angiography showed partial occlusive thrombus in aorta at the level of origin of SMA and renal arteries.
Corresponding Author: Mani Agila Saravanan, No. 5. Thuru Nagar Colony, III Street, Vadapalani, Chennai-600026, Tamilnadu, India.

E-mail: agilajeevamoni@gmail.com

DOI: 10.14260/jemds/2019/661

Financial or Other Competing Interests: None.

How to Cite This Article:

Saravanan MA, Sowmiya KP. A rare case of young hypertension- disease beyond the arch. J. Evolution Med. Dent. Sci. 2019;8(40):3044-3045, DOI: $10.14260 /$ jemds $/ 2019 / 661$

Submission 05-08-2019,

Peer Review 18-09-2019,

Acceptance 25-09-2019,

Published 07-10-2019. 


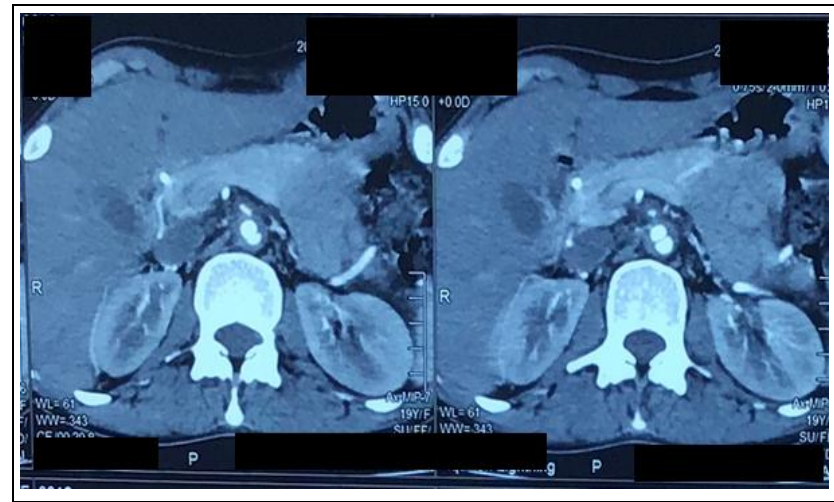

Figure 1. MRI Showing Partial Occlusive Thrombus in Aorta at the Level of Origin of Superior Mesenteric Artery and Renal Arteries

DTPA scan (Diethylenetriamine pentaacetic acid scan) revealed hemodynamically significant renovascular hypertension in right renal system. Based on history, clinical examination and investigation, patient was diagnosed as a case of Takayasu arteritis according to American College of Rheumatology criteria. Patient was referred to higher centre for further management.

\section{DISCUSSION}

MAS was first described by Sen et al. in $1963 .^{3}$ It is a rare disease accounting to $0.5-2 \%$ of all cases of aortic narrowing. The disease is characterized by segmental narrowing of the descending thoracic or abdominal aorta or both. Renal artery stenosis will be seen in $80 \%$ of cases. It involves SMA, IMA and celiac axis in $25 \%$. MAS is described in Takayasu arteritis, fibromuscular dysplasia, neurofibromatosis, ${ }^{4}$ Mucopolysaccharidosis, turner's, Alagille syndrome, William's syndrome. ${ }^{5}$

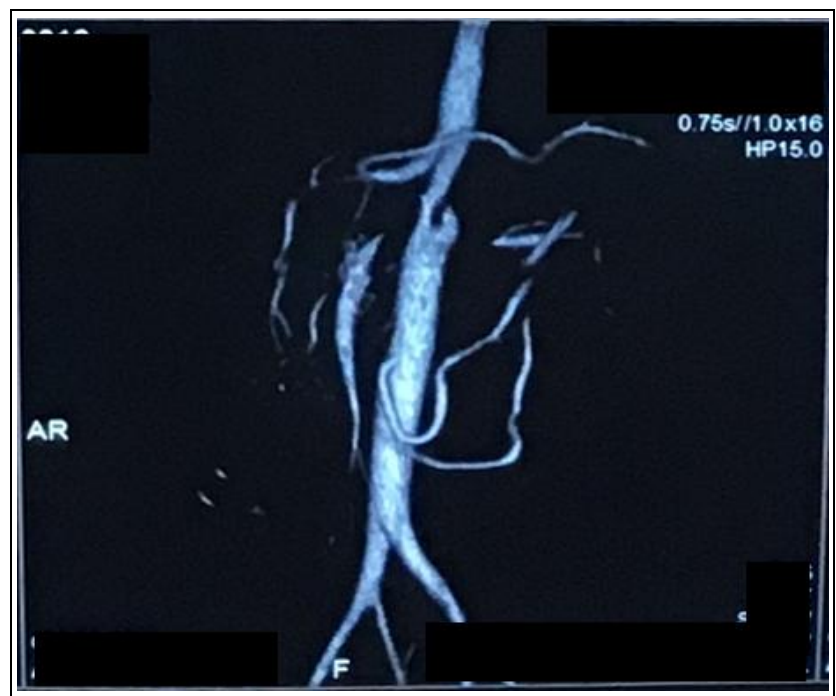

Figure 2. MRI Showing Luminal Narrowing of Abdominal Aorta (just Proximal to the Origin of Renal Vessels) and the Proximal part of Renal Arteries
The disease is an important cause of hypertension in children and young adults. Patients with MAS predominantly present with refractory hypertension and if left untreated, patients develop intermittent claudication of legs, congestive cardiac failure, renal insufficiency and symptoms of hypertension associated end organ damage. ${ }^{6}$

Angiography is the gold standard investigation for diagnosis. Treatment of choice remains surgical revascularisation. Medical management can be used to bridge the surgery. It is used in control of hypertension and in acute phase of aorto-arteritis. Surgical correction is done when associated with aneurysmal degeneration, aortoiliac occlusive disease and severe hypertension.

\section{CONCLUSIONS}

Angiography is the gold standard investigation for diagnosis of Mid Aortic Syndrome. Treatment is necessary because of severe complications secondary to hypertension. Surgery remains the treatment of choice. We report this case for its rarity.

\section{REFERENCES}

[1] Cohen JR, Birnbaum E. Coarctation of the abdominal aorta J Vasc Surg 1988;8(2):160-4.

[2] Coleman DM, Eliason JL, Ohye RG, et al. Long-segment thoracoabdominal aortic occlusions in childhood. J Vasc Surg 2012;56(2):482-5.

[3] Sen PK, Kinare SG, Engineer SD, et al. The middle aortic syndrome. Br Heart J 1963;25:610-8.

[4] Connolly JE, Wilson SE, Lawrence PL, et al. Middle aortic syndrome: distal thoracic and abdominal coarctation, a disorder with multiple etiologies. J Am Coll Surg 2002;194(6):774-81.

[5] Radford DJ, Pohlner PG. The middle aortic syndrome: an important feature of Williams' syndrome. Cardiol Young 2000;10(6):597-602.

[6] Ayik F, Engin C, Ertugay S, et al. Surgical repair of middle aortic syndrome in a three-year-old patient. J Card Surg 2011;26(6):659-62. 